\title{
PESQUISA SURVEY COM O OBJETIVO DE COLETAR DADOS A RESPEITO DO MERCADO DE AUTOMAÇÃO RESIDENCIAL NO BRASIL.
}

Eduardo Pimentel Rebouças'; Valéria Loureiro da Silva²

1 SENAI CIMATEC; Salvador/Bahia; eng.pimentelreboucas@gmail.com

2 SENAI CIMATEC; Salvador/Bahia; valeria.dasilva@fieb.org.br

Resumo: O presente trabalho tem como objetivo coletar dados a respeito do mercado de automação residencial no Brasil por meio de uma pesquisa survey. A população estudada no trabalho consistiu de profissionais e personagens do setor de automação presentes na $31^{\text {a }}$ Feira Internacional da Indústria Elétrica, Eletrônica, Energia e Automação - FIEE 2019. Os resultados indicaram que as soluções com maior demanda foram as relacionadas com sistemas de câmeras e segurança, confirmando com os resultados de outras perguntas que consideraram o setor de segurança patrimonial como o de maior demanda entre o público da amostra.

Palavras-Chaves: Automação; Residencial; loT; Mercado; Soluções.

\section{SURVEY FOR THE COLLECTION OF DATA ABOUT THE RESIDENTIAL AUTOMATION MARKET IN BRAZIL.}

\begin{abstract}
This paper aims to collect data about the home automation market in Brazil through a survey. The study population consisted of professionals and characters from the automation sector present at the 31st International Fair of Electrical, Electronics, Energy and Automation - FIEE 2019. The results indicated that the most demanding solutions were related to cameras and security systems., confirming with the results of other questions that considered the property security sector as the most demanded among the sample public.
\end{abstract}

Keywords: Automation; Residential; IoT; Marketplace; Solutions. 


\section{INTRODUÇÃO}

De acordo com o BNDES (2018) o universo da Internet das Coisas (Internet of Things - IoT) tem se mostrado como uma oportunidade única para os mercados consumidores mundiais. Até 2025, no mundo, a loT terá um impacto econômico de US\$ 4 a 11 trilhões, maior que a robótica avançada, as tecnologias cloud, e até mesmo a internet móvel. No Brasil, o impacto potencial é de US\$50 a 200 bilhões por ano, valor que representa cerca de $10 \%$ do PIB brasileiro. O interesse e preocupação em relação aos impactos da loT já se mostram presentes nas ações do governo brasileiro. Ao longo do ano de 2018, o Banco Nacional de Desenvolvimento (BNDES) e o Ministério da Ciência, Tecnologia, Inovações e Comunicações (MCTIC) investiram R\$ 17,4 milhões para a elaboração de um estudo técnico independente através de um consórcio formado pela consultoria McKinsey, Centro de Pesquisa e Desenvolvimento em Telecomunicações (CPqD). O estudo denomina-se "Internet das Coisas: um plano de ação para o Brasil" (2018).

O estudo "Internet das Coisas: um plano de ação para o Brasil" (2018) traz que o mercado formado pelas aplicações loT é extremamente vasto e tem potencial de aplicação nas mais diversas áreas da economia, como: agronegócios, industrias, veículos, logística, saúde, escritórios, cidades e residências.

O presente trabalho tem como objetivo coletar dados a respeito do mercado de automação residencial no Brasil por meio de uma pesquisa survey. Com o aprofundamento dos estudos pode-se comprovar que a maioria dos trabalhos científicos voltados para automação residencial concentra seus esforços em analisar e entender a parte mais técnica, como componentes essenciais e arquiteturas de comunicação máquina-máquina. Pouco se vê a respeito da interação homemmáquina e de aspectos sócio e econômicos relacionados ao setor. Um dos únicos trabalhos encontrados com tais características foi o publicado na revista Emeraldlnsigth realizado por Heetae Yang Hwansoo Lee Hangjung Zo (2017). Então, a partir desta lacuna, este trabalho tem como objetivo coletar dados a respeito das soluções e personagens que compõem o mercado de automação residencial no Brasil.

\subsection{AUTOMAÇÃO RESIDENCIAL}

De acordo com o relatório da Industry Today (2018) estima-se que o mercado de Automação Residencial atinja globalmente a cifra de US\$113,82 bilhões em 2025, partindo de US\$35,24 bilhões em 2016. Este mercado é descrito como uma variedade de recursos locais ou baseados em nuvem que permitem a uma casa controlar e monitorar suas várias operações.

Nas economias mais desenvolvidas, o cenário para as chamadas "casas inteligentes" tem evoluído de maneira muito positiva. A crescente popularização de tecnologias tem contribuído para a alavancagem do setor, os preços dos equipamentos decrescem ano após ano e o consumidor está cada vez mais familiarizado com a ideia de uma casa inteligente. Soma-se a isto a oferta abundante 
e cada vez mais acessível de serviços de comunicação, como acesso em banda larga, diversas modalidades de conteúdo digital, downloads de músicas e filmes, e assim por diante, e temos um ambiente muito propício para o desenvolvimento dos chamados "sistemas domóticos" (no Brasil, assim como nos Estados Unidos, a nomenclatura mais usada é Automação Residencial, enquanto na Europa o termo usual é Domótica). (Relatório Aureside, 2018).

Domingues (2013) traz que as crescentes exigências da sociedade com relação ao conforto de seus lares se somam com a possibilidade de melhorar o desempenho energético com auxílio de uma gestão inteligente de recursos, como a água e a energia. Proporcionando uma diminuição dos desperdícios e consequentemente uma diminuição de custos financeiros em casas automatizadas.

Segundo o Instituto Brasileiro de Geografia e Estatística (IBGE) a pesquisa realizada no ano de 2016 apurou que existem 69,3 milhões de domicílios particulares permanentes no Brasil, e de acordo com a Associação Brasileira de Automação Residencial e Predial (Aureside, 2018) existem 300 mil domicílios particulares automatizados no Brasil. Ou seja, a automação está presente em apenas 2,61\% dos domicílios no Brasil e existe um mercado de $97,69 \%$ de domicílios a ser explorado.

\subsubsection{O MERCADO E SEUS PERSONAGENS}

Esta sessão busca identificar os principais personagens existentes no mercado de automação residencial brasileiro. Entende-se "personagem" como qualquer ser que tenha relevância perante ao mercado de automação residencial.

Figura 1. Personagens do mercado de automação residencial.

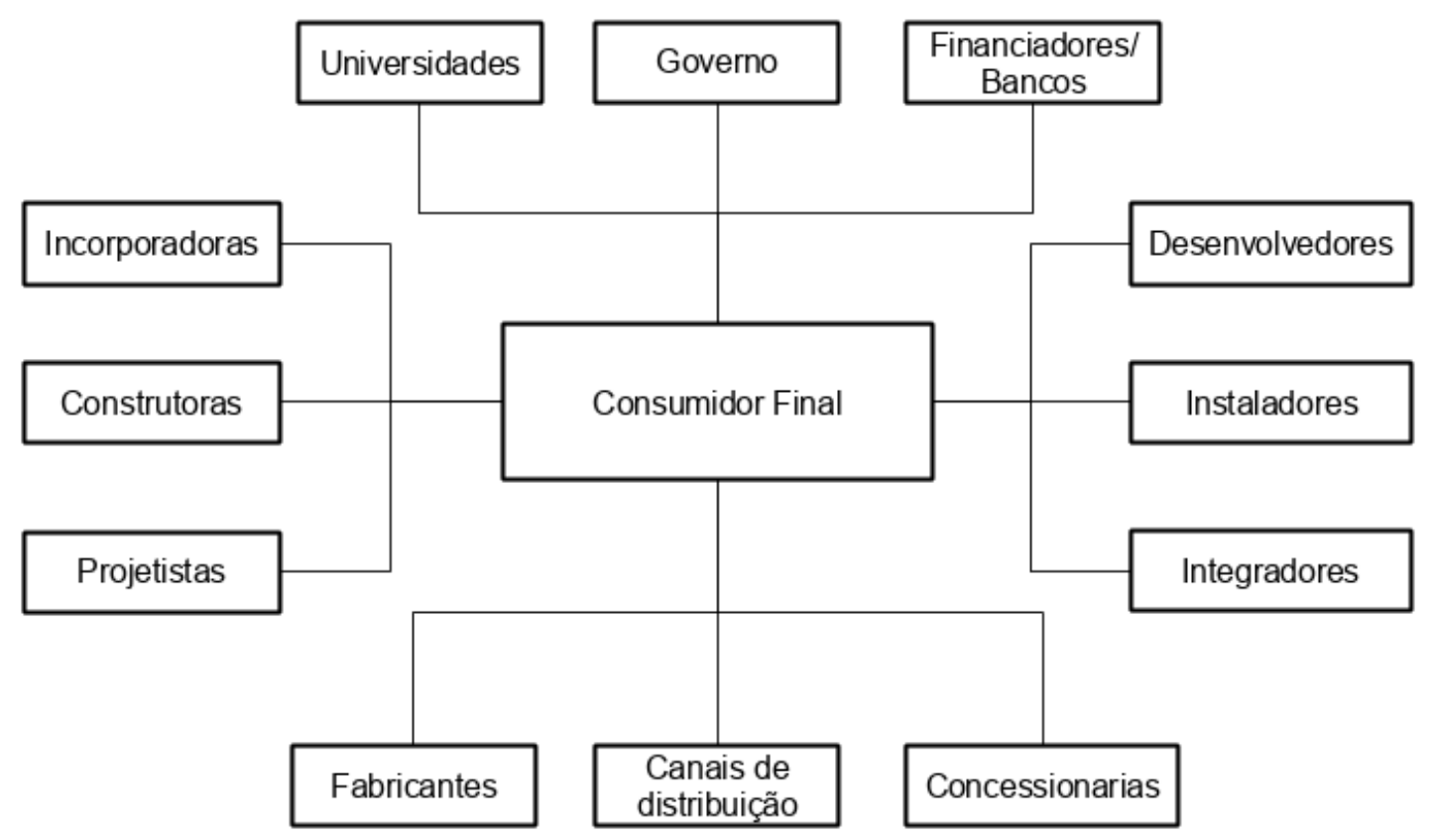


Universidades: Responsáveis por analisar e desenvolver conhecimento técnico para fundamentar o senso crítico e a inserção das novas tecnologias ao mercado.

Governo: Autoridade governante de uma nação ou unidade política, que tem como finalidade regrar e organizar a sociedade. Tem um papel de extrema importância e está diretamente ligado aos mecanismos de fomento ao desenvolvimento tecnológico e científico.

Financiadores: São instituições financeiras responsáveis por disponibilizar capital para que o mercado se desenvolva.

Desenvolvedores e licenciadores: Empresas de software, alianças de diversos fabricantes em torno de um protocolo comum de interoperabilidade, laboratórios de eletrônica, robótica e mecatrônica públicos e privados, universidades e outras entidades afins

Integradores, Instaladores e Projetistas: Cumprem atividades múltiplas, como projeto, especificação, fornecimento, instalação, programação e pós-venda dos sistemas de automação residencial. Representam um elo muito importante na cadeia mercadológica, pois sem eles se tornaria muito difícil para os Fabricantes colocar seus produtos no mercado consumidor.

Fabricantes: Podem ser grandes grupos multinacionais, subsidiárias, importadoras e fabricas nacionais. São responsáveis por fabricar os dispositivos de automação.

Concessionarias e operadoras de telecomunicação: Responsáveis por disponibilizar redes telecomunicação para estruturar as novas tecnologias.

Incorporadoras, Construtoras: São responsáveis por construir novos domicílios e estão diretamente ligadas com a infraestrutura das instalações prediais, devem estar atentos as mudanças do mercado e podem se beneficiar do valor agregado que a automação traz a seu produto final.

Canais de distribuição: São os canais através do qual os produtos passam até a chegada na residência do consumidor final.

\subsubsection{SOLUÇÕES DE AUTOMAÇÃO RESIDENCIAL}

Esta sessão busca identificar as principais soluções de automação residencial presentes no mercado de automação residencial brasileiro. Entende-se "solução de automação" como qualquer solução desenvolvida a partir dos conceitos base de automação que solucione um problema do cotidiano residencial.

É importante salientar a diferença entre "solução" e "tecnologia". Usando como exemplo o acionamento a distância de uma lâmpada, temos uma diversidade de tecnologias que podem proporcionar este acionamento, entretanto independente da tecnologia escolhida a solução será sempre a mesma, acionamento a distância de uma lâmpada. 
Foi realizado um mapeamento dos principais produtos/tecnologias de automação residencial existentes no mercado, através deste mapeamento foram identificadas doze soluções de automação residencial.

1) Vídeo porteiro eletrônico. 2) Fechadura com biometria ou cartão de acesso. 3) Controle a distância da iluminação. 4) Controle a distância de Home Theater, som ambiente e eletrodomésticos. 5) Sistema de câmeras inteligente com alerta de atividades. 6) Dispositivo de alimentação animal semiautônomo. 7) Controle e gerenciamento da temperatura e umidade. 8) Monitoramento em tempo real do consumo de água, luz e gás. 9) Robô aspirador de pó autônomo. 10) Irrigação automática. 11) Dispositivo que ajuda a lembrar de tomar as medicações. 12) Monitoramento de crianças e idosos.

\section{METODOLOGIA}

O presente trabalho tem como objetivo coletar dados a respeito do mercado de automação residencial no Brasil por meio de uma pesquisa survey com propósito exploratório. De acordo com Pinsonneault \& Kraemer (1993) este propósito tem por objetivo familiarizar-se com o tópico ou identificar conceitos iniciais sobre um tópico, dar ênfase na determinação de quais conceitos devem ser medidos e como serem medidos, buscar descobrir novas possibilidades e dimensões da população de interesse.

Perrien, Cheron e Zins (1984) consideram que o processo de amostragem é composto pela definição da população-alvo. Para a elaboração do processo de amostragem foi definido um público-alvo de acordo com alguns dos personagens que compõem o mercado de automação brasileiro. A população escolhida para este survey foi a dos profissionais envolvidos com as atribuições eletrotécnicas do setor, pode se dizer que os integrantes desta população têm importantes funções que começam na produção dos equipamentos e se estende até a instalação na residência do cliente final. Os personagens escolhidos para compor a amostra foram os seguintes: Fabricantes, Instaladores, Projetistas, Integradores, Desenvolvedores, Vendedores, Estudantes e Especificadores.

Em relação ao número pontos no tempo em que foram coletados os dados, a pesquisa pode ser designada como um corte-transversal, onde a coleta dos dados ocorre em um único momento, no dia 25 de julho de 2019 na cidade de São Paulo SP, prédio de exposições e eventos Expo São Paulo onde estava sendo realizado a $31^{a}$ Feira Internacional da Indústria Elétrica, Eletrônica, Energia e Automação - FIEE 2019.

O instrumento utilizado para a coleta e armazenamento dos dados foi a plataforma digital SurveyMonkey, especializada em questionários online e atualmente referência no setor de surveys. Segundo dados da própria SurveyMonkey $98 \%$ das maiores empresas do mundo listadas na Fortune são seus clientes. A escolha da plataforma se justifica por conta das funcionalidades de elaboração e praticidade de armazenamento dos dados. Foram realizados testes também com as plataformas 


\section{\begin{tabular}{l|l} 
CIRCULAR ECONOMY & ECONOMIA CIRCULAR
\end{tabular}}

Google Forms e Survio antes da escolha do SurveyMonkey como instrumento para a elaboração e aplicação da pesquisa.

O questionário aplicado na FIEE consistiu em 18 perguntas sendo elas: 1 (uma) pergunta para o termo de aceite; 7 (sete) perguntas de classificação demográfica contendo sexo, idade, tipo de residência, número de pessoas que moram na residência, nível de escolaridade, profissão atual, e ticket médio dos serviços prestados; 3 (três) perguntas de sim ou não, relacionadas ao mercado de automação; 1 (uma) matriz para o respondente avaliar a demanda das soluções; 1 (uma) pergunta a respeito dos segmentos de mercado; 4 (quatro) perguntas abertas; e 1 (uma) pergunta com o respondente deixar o e-mail para receber os resultados da pesquisa.

Durante a elaboração do trabalho foi realizado uma classificação das soluções em categorias de acordo com o nível de interação da automação com o ser humano e com o principal valor proporcionado ao usuário final. De acordo com Oliveira (2016) os valores para o usuário estão relacionados com categorias onde se destaca cinco maiores áreas de benefício da automação residencial, elas são: Conforto e comodidade, Segurança Patrimonial, Economia de Tempo, Saúde e Economia de Dinheiro.

Tabela 1. Soluções, valor para o usuário e nível de interação.

\begin{tabular}{|c|c|c|c|c|c|}
\hline \multirow[b]{2}{*}{ Soluções/(NÍVEL DE INTERAÇÃO) } & \multicolumn{5}{|c|}{ Principal valor paro o usuário } \\
\hline & $\begin{array}{l}\text { Economia de } \\
\text { dinheiro }\end{array}$ & $\begin{array}{c}\text { Economia de } \\
\text { tempo }\end{array}$ & Saúde & Segurança & $\begin{array}{l}\text { Conforto e } \\
\text { comodidade }\end{array}$ \\
\hline $\begin{array}{l}\text { Dispositivo de alimentação animal semi-autônomo. (SEMI- } \\
\text { AUTONOMO) }\end{array}$ & & & & & $\mathrm{x}$ \\
\hline $\begin{array}{l}\text { Controle e gerenciamento da temperatura e umidade. (SEMI- } \\
\text { AUTONOMO) }\end{array}$ & & & & & $\mathrm{x}$ \\
\hline Robô aspirador de pó autônomo. (SEMI-AUTONOMO) & & $\mathrm{x}$ & & & \\
\hline Irrigação automática. (SEMI-AUTONOMO) & & $\mathrm{x}$ & & & \\
\hline $\begin{array}{l}\text { Controle a distância do Home Theater, som ambiente e } \\
\text { eletrodomésticos. (CONTROLE) }\end{array}$ & & & & & $\mathrm{x}$ \\
\hline $\begin{array}{l}\text { Controle a distância da iluminação por smartphone ou tablet. } \\
\text { (CONTROLE) }\end{array}$ & & & & & $\mathrm{x}$ \\
\hline Vídeo porteiro eletrônico. (CONTROLE) & & & & $\mathrm{x}$ & \\
\hline $\begin{array}{l}\text { Fechadura eletrônica com biometria ou cartão de acesso. } \\
\text { (CONTROLE) }\end{array}$ & & & & $\mathrm{x}$ & \\
\hline $\begin{array}{l}\text { Dispositivo que-lhe ajuda a lembrar de tomar as medicações. } \\
\text { (MONITORAMENTO) }\end{array}$ & & & $\mathrm{x}$ & & \\
\hline Monitoramento de crianças e idosos. (MONITORAMENTO) & & & $\mathrm{x}$ & & \\
\hline $\begin{array}{l}\text { Sistema de câmeras inteligente com alerta de atividades } \\
\text { suspeita. (MONITORAMENTO) }\end{array}$ & & & & $\mathrm{x}$ & \\
\hline $\begin{array}{l}\text { Monitoramento em tempo real do consumo de água, luz e } \\
\text { gás. (MONITORAMENTO) }\end{array}$ & $\mathrm{x}$ & & & & \\
\hline Total & 1 & 2 & 2 & 3 & 4 \\
\hline
\end{tabular}




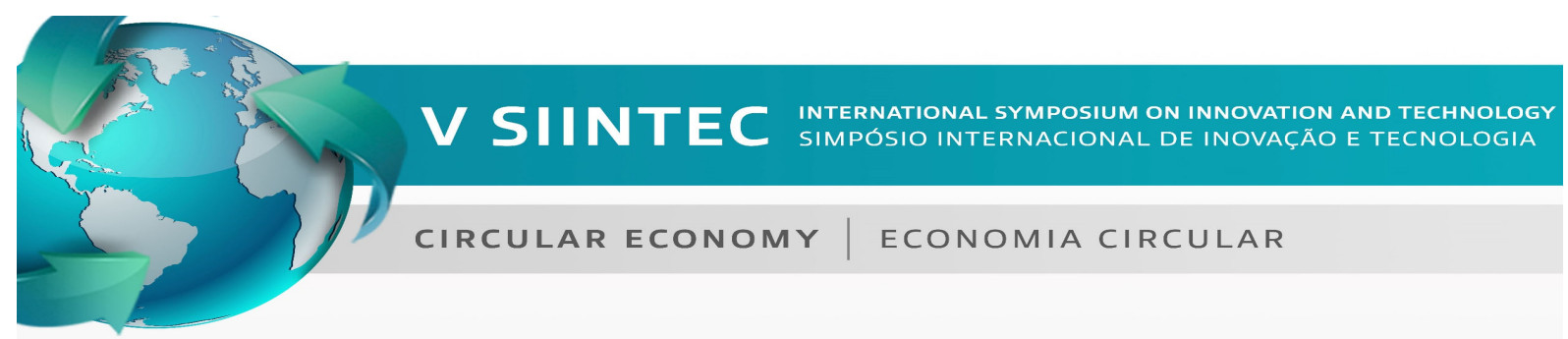

\section{RESULTADOS E DISCUSSÃO}

Foram coletados 67 questionários, 60 dos quais possuíam todas as perguntas respondidas completamente. Foram utilizadas na análise abaixo apenas as respostas dos questionários respondidos completamente.

A população de respondentes atendeu os objetivos de incluir personagens cobrindo o segmento de projeto, fabricação e instalação de componentes e/ou sistemas de automação residencial. Dos respondentes, $19,35 \%$ se descreveram como fabricantes, $17,74 \%$ como desenvolvedores, $12,9 \%$ como estudantes, $11,29 \%$ como projetistas, $8,06 \%$ como instaladores, $6,45 \%$ como vendedores, 4,84\% integradores, $1,61 \%$ como especificador e $17,74 \%$ como outros. A população masculina de respondentes corresponde a $72,58 \%$ e a feminina $27,42 \%$ do total. Com relação à idade, $11,29 \%$ dos respondentes têm menos de 20 anos, $40,32 \%$ têm entre 21 a 29 anos, $29,03 \%$ entre 30 a 39 anos, $12,90 \%$ entre 40 a 59 anos, e 6,45\% têm 60 anos ou mais. Já com relação ao nível de escolaridade $3,23 \%$ dos respondentes completaram o ensino fundamental, $14,52 \%$ ensino médio, $25,81 \%$ ensino técnico, $35,48 \%$ ensino superior e $20,97 \%$ pós-graduação.

Quando perguntados, $51,52 \%$ dos respondentes disseram que trabalham com alguma tecnologia que possa contribuir com o conceito de Casas Inteligentes (Smart Home) e as palavras mais utilizadas para responder à pergunta aberta: "O que te vem à cabeça quando ouve a expressão "Automação Residencial"? ", em ordem decrescente, foram: Casa Inteligente, Praticidade, Tecnologia, Controle, Comodidades e Conforto. A grande maioria dos respondentes, 90,32\%, considera que incorporar tecnologias a residências ajuda na hora da venda de um imóvel. No entanto, apenas 30,65\% dos respondentes possui alguma solução de automação em sua própria residência. Esses resultados, aparentemente contraditórios, indicam a existência de barreiras para a adoção da tecnologia que precisam ser melhor investigadas.

As palavras mais utilizadas nas respostas para a pergunta aberta: "Das tecnologias que você trabalha quais são os mais requisitados pelos clientes? ", em ordem decrescente, foram: Controle, Automação, Segurança, Iluminação, Consumo, Câmeras e Energia.

Em relação a pergunta aberta: "Quais possibilidades e benefícios você enxerga para o futuro da automação residencial no Brasil? ". As palavras mais utilizadas nas respostas em ordem decrescente foram: Mercado, Segurança e Possibilidades.

As respostas para a pergunta aberta: "Quais barreiras e dificuldades você enxerga para a adoção em massa do conceito de Casas Inteligentes aqui no Brasil? ", mostram que $84,61 \%$ considera que o "alto custo" de aquisição da tecnologia é a principal barreira para adoção. A questão "cultural" e "acessibilidade" é considerada como uma barreira para adoção por $11,53 \%$ e $3,84 \%$ dos respondentes, respectivamente.

As respostas à pergunta "De acordo com a sua visão de mercado classifique a demanda das seguintes soluções em automação residencial. " São apresentadas na tabela 2. Essas respostas indicam que, na percepção dos desenvolvedores e 
instaladores, a maior demanda está ligada a sistemas ligados a segurança, confirmada pelas respostas à pergunta "Selecione o segmento abaixo que você acredita ter a maior demanda de mercado quando se trata de automatizar uma residência.", onde $37,70 \%$ dos respondentes selecionou o segmento de Segurança Patrimonial, $27,87 \%$ o de Controle por smartphone ou voz de sistemas e eletrodomésticos, $14,75 \%$ o de Monitoramento e gerenciamento do consumo energético, $11,48 \%$ o de Saúde e cuidados especiais e $8,20 \%$ o de Sistemas autônomos de limpeza, irrigação e alimentação animal.

Tabela 2. Respostas matriz soluções/demanda.

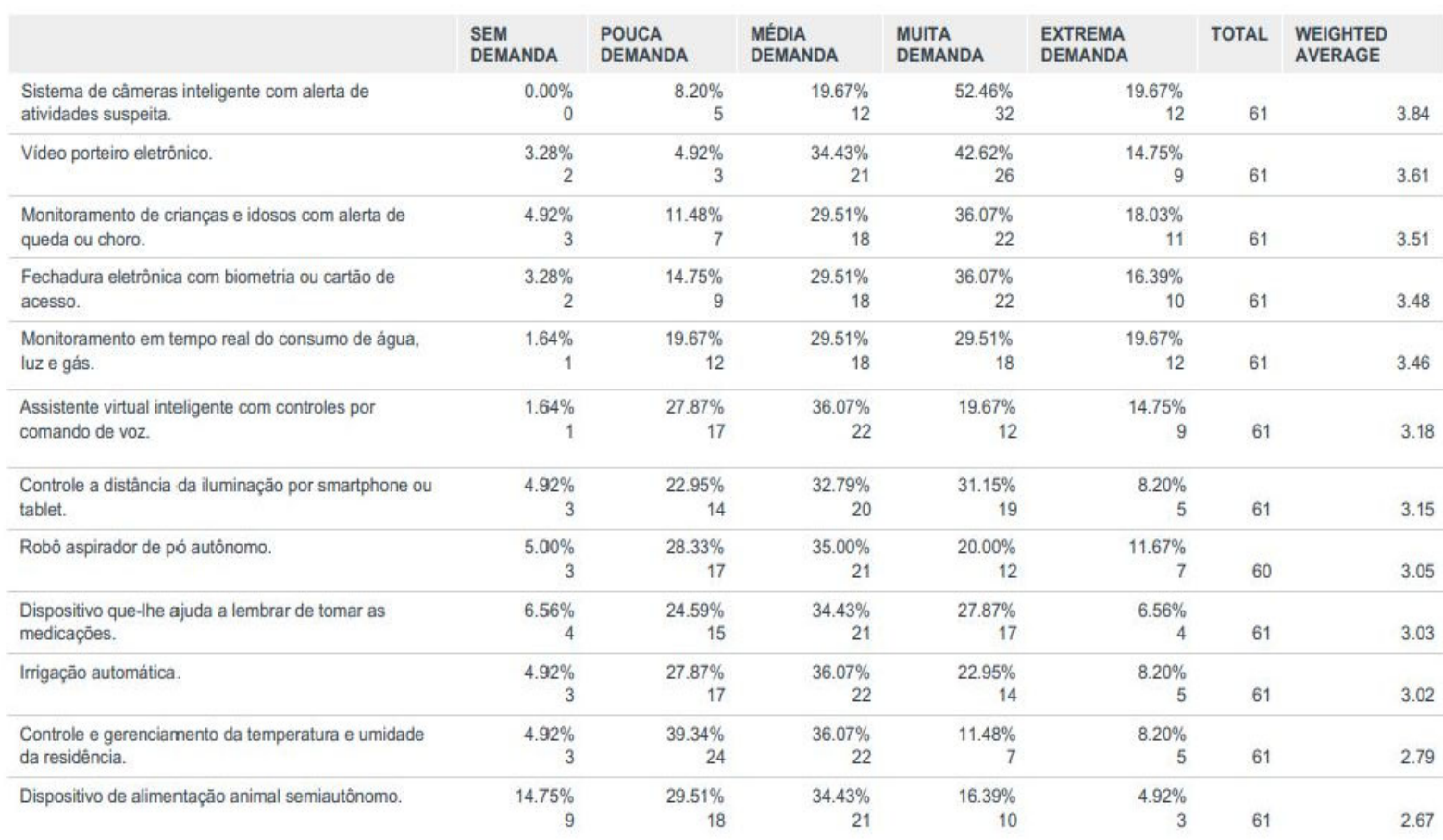

As palavras mais utilizadas nas respostas para a pergunta aberta: "Das tecnologias que você trabalha quais são os mais requisitados pelos clientes? ", em ordem decrescente, foram: Controle, Automação, Segurança, lluminação, Consumo, Câmeras e Energia.

Em relação a pergunta aberta: "Quais possibilidades e benefícios você enxerga para o futuro da automação residencial no Brasil? ". As palavras mais utilizadas nas respostas em ordem decrescente foram: Mercado, Segurança e Possibilidades.

As respostas para a pergunta aberta: "Quais barreiras e dificuldades você enxerga para a adoção em massa do conceito de Casas Inteligentes aqui no Brasil? ", mostram que $84,61 \%$ considera que o "alto custo" de aquisição da tecnologia é a principal barreira para adoção. A questão "cultural" e "acessibilidade" é considerada como uma barreira para adoção por $11,53 \%$ e $3,84 \%$ dos respondentes, respectivamente.

Cinquenta e três dos 60 respondentes se interessaram pelos resultados do trabalho e deixaram seus e-mails. 


\section{CONCLUSÃO}

Pretendeu-se neste trabalho coletar dados a respeito do mercado de automação residencial brasileiro com o objetivo de identificar as principais aplicações e barreiras para adoção através da aplicação de um survey. A população estudada no survey consistiu de profissionais dos setores de elétrica, eletrônica, energia e automação. Os resultados do survey indicam que as soluções com maior demanda foram as relacionadas com sistemas de câmeras e segurança, confirmando os resultados encontrados para a pergunta em relação ao segmento com maior demanda: segurança patrimonial. O fator primordial relatado como barreira para a adoção da tecnologia foi o "custo de aquisição" seguido de "cultura" e acessibilidade.

Diante de um cenário tão promissor e revolucionário que estamos vivendo, decorrente da crescente evolução de novas tecnologias, é inquietante constatar que a realidade dos trabalhos científicos com o enfoque na área de automação residencial se restringe em sua maior parte em analisar a arquitetura técnica e as tecnologias embarcadas nos sistemas, pouco se vê a respeito do fator humano, de como a população está entendendo a problemática, e principalmente das consequências decorrentes desta crescente e cada vez mais próxima interação homem-máquina.

\section{REFERÊNCIAS}

[1] AURESIDE, Relatório AURESIDE 2018. 2018. Disponível em: < http://www.aureside.org.br>. Acesso em: 08 ago. 2019.

[2] BNDES (2017). Plano de Ação. Disponível em: https://www.bndes.gov.br/wps/wcm/connect/site/ f9582d36-4355-4638-b931e2e53af5e456/8B-relatorio-final-plano-de-acao-produto-

ambienteregulatorio.pdf?MOD=AJPERES\&CVID=m5WL-KC. Acesso em: 8 ago. 2019

[4] DOMINGUES, Ricardo Gil; DE PINA FILHO, Armando Carlos. A IMPORTÂNCIA DA DOMÓTICA PARA A SUSTENTABILIDADE DAS CIDADES. Blucher Engineering Proceedings, v. 2, n. 2, p. 303-315, 2015.

[5] HEETAE YANG HWANSOO LEE HANGJUNG ZO , (2017)," User acceptance of smart home services: an extension of the theory of planned behavior ", Industrial Management \& Data Systems, Vol. 117.

[6] MCKINSEY \& COMPANY. Unlocking the Potential of the Internet of Things. abril 2015.

[7] OLIVEIRA. M. U. M. Domótica: a casa do futuro já presente. Revista Especialize On-line IPOG - Goiânia - 12 $2^{\mathrm{a}}$ Edição Nº 012, Vol.01/2016, Dezembro. 2016.

[8] PERRIEN, J.; CHERON, E. J.; ZINS, M. Méthodes d'échantillonnage. Recherche en marketing: méthodes et décisions, p. 203-241, 1984. 
[9] PINSONNEAULT, Alain; KRAEMER, Kenneth. Survey research methodology in management information systems: an assessment. Journal of management information systems, v. 10, n. 2, p. 75-105, 1993. 